Article

\title{
Social Capital and Citizens' Attitudes towards Migrant Workers
}

\author{
Abdoulaye Diop ${ }^{1, *}$, Yaojun Li ${ }^{2,3}$, Majed Mohammed H. A. Al-Ansari ${ }^{1}$ and Kien T. Le ${ }^{1}$ \\ ${ }^{1}$ Social and Economic Survey Research Institute, Qatar University, Doha, Qatar; E-Mails: adiop@qu.edu.qa (A.D.), \\ mansari@qu.edu.qa (M.M.H.A.A.-A.), kienle@qu.edu.qa (K.T.L.) \\ 2 Department of Sociology, University of Manchester, Manchester, M13 9PL, UK; E-Mail: yaojun.li@manchester.ac.uk \\ ${ }^{3}$ Cathie Marsh Institute for Social Research, University of Manchester, Manchester, M13 9PL, UK \\ * Corresponding author
}

Submitted: 13 October 2016 | Accepted: 15 December 2016 | Published: 28 March 2017

\begin{abstract}
This study examines Qatari citizens' attitudes toward migrant workers. While much research has been conducted on citizens' attitudes toward the abolition, tightening, or loosening of the Kafāla system in the Gulf Cooperation Council (GCC) countries with regard to migrant workers' residency rights, and on their contribution to the economic development of these countries, little is known about how citizens' religiosity and social engagement impact their acceptance of migrant workers. In the present study, we address this question by examining the effects of religious and social capital on Qatari citizens' preferences for having Arab and Western migrant workers as neighbours, drawing on data from two nationally representative surveys in Qatar. The results indicate that, even after controlling for a wide range of socio-demographic attributes, social capital in terms of trust and bridging social ties has a strong effect on the Qatari nationals' preferences.
\end{abstract}

\section{Keywords}

Gulf Cooperation Council countries; kafāla system; migrant workers; public attitudes, social capital

\section{Issue}

This article is part of the issue "International Migration and Ethnic Integration", edited by Yaojun Li (University of Manchester, UK) and Anthony Heath (University of Oxford, UK).

(C) 2017 by the authors; licensee Cogitatio (Lisbon, Portugal). This article is licensed under a Creative Commons Attribution 4.0 International License (CC BY).

\section{Introduction}

The influence of migration on ethnic diversity and community cohesion has been extensively studied in the USA and Europe. Scholars have generally found that large inflows of migrants change the demographic composition of the receiving countries and have a strong and largely negative impact on community cohesion. Consequently, much of the discussion about migration is focused on the mainstream population's (or nationals') attitudes towards, and the socio-economic integration of, the migrant workers and their children. However, in the Gulf Cooperation Council (GCC) countries, surprisingly few studies have investigated these issues. In this context, the migration literature has mostly been centred around understanding the recruitment of migrant workers, their lives and working conditions in the host countries, their re- mittances to family members back home, the impact of remittances on the lives of their family members, and economic development in the sending countries. It was not until recently that the focus shifted slightly to an examination of the attitudes of nationals towards migrant workers and the kafāla system which regulates their employment and residential status in the GCC countries. In the GCC countries, 'foreigners' are guest workers who have little prospect of becoming naturalized citizens of the countries even though they may work and live alongside nationals.

More than anywhere else in the world, the countries of the Arabian Gulf are dependent on foreign labour to sustain their economic growth and development. Across the region, these workers play a vital role, carrying out jobs that are both mundane (e.g. janitorial services, domestic work) and critical to the national economy of 
these countries (e.g. construction, natural resource extraction). Unlike in Europe, in the GCC generally, and in Qatar and the UAE in particular, these 'foreigners' constitute the majority of the population at the present time. These workers also bring with them their various religious traditions and customs, introducing significant diversity to countries for which Islam has long been overwhelmingly dominant. The growing presence of these workers has led GCC nationals to re-examine their nationhood and their place within society. According to some critics, these demographic changes have led some nationals to look inward, becoming more insular and less engaged civically within their local communities and neighbourhoods. This may be more pronounced in Qatar with the commitment to the FIFA 2022 World Cup. Such commitment has maintained or increased the need for migrant workers in the country to complete the infrastructure development projects but nationals' attitudes towards 'foreigners' have so far remained underresearched.

In this context, we thought it high time that a systematic study be conducted which linked nationals' religious and social-civic engagement with their attitudes towards migrant workers. We use Qatar as a case study because it typifies Gulf countries, which have a very highly proportion of migrant workers in the population (Ministry of Developmental Planning and Statistics, 2016). The insight from the study of nationals' attitudes to and their preferences for migrant workers as neighbours, a fairly intimate form of personal interaction in the Qatari context, has important implications both for the on-going debate on immigration ${ }^{1}$ and social cohesion, and for the socioeconomic integration and well-being of immigrants. To carry out the research, we have used two national representative surveys that we conducted in Qatar. We find that religious affiliation, social trust, and bridging social ties play a significant role in citizens' attitudes towards migrant workers.

This paper is structured as follows. In the next section, we give a review of the literature on social capital, social cohesion, and social trust. Based on this literature, we introduce our hypotheses, to be followed by the presentation of our data and findings. We conclude the paper with some discussions and suggestions for future research.

\section{Literature Review}

Social capital is a complex and highly controversial concept; nonetheless, it is widely used by scholars in various social science disciplines as a measure of connectedness at the individual, community, and national levels. Social capital theorists use the term to refer to resources inherent in the social networks, whether such resources are informational, material or psychological (Bourdieu, 1986; Coleman, 1988; Lin, 2001; Putnam, 2000). Such resources could be beneficial to individuals in terms of chil- dren's education, job acquisition, career advancement, health enhancement, and a range of other outcomes. The benefits are not only for those in the networks, but extend to people who are onlookers or who are not directly involved in the networks. Thus, social capital is assumed to be helpful for community building too. Researchers tend to differentiate between two types of social capital: bonding and bridging (Putnam, 2000). Bonding refers to connections and networks within a homogeneous group, while bridging refers to social ties among people with dissimilar characteristics such as race, ethnicity, education or personal attributes. As such, bridging is more related to the concept of social cohesion (Cheong, Edwards, Goulbourne, \& Solomos, 2007) and is a point of interest for this analysis. A more comprehensive definition of bridging social capital is offered by Putnam, who says that it 'concerns voluntary associations and horizontal ties based on common interests that transcend heterogeneous differences of ethnicity, religion and socio-economic status' (2000, p.22).

Scholars have different views on how to assess the relationship between social cohesion and social capital. Putnam (2000) suggested that bridging social ties are a means of 'getting ahead' in society, as opposed to bonding social ties, which he describes as helping people to 'get by'. The two forms of social capital tend to go hand in hand although they might serve different purposes: chicken soup for the sick and 'sleeve-rolling' for community building. He holds that, in order to maintain and enhance community cohesion, people need to acquire connections with members of other groups who may possess different types of social resources. However it is important to note, at this juncture, that as a political scientist, Putnam's main interest was in the effect of social capital on social-political governance. Much of his analysis tends to link the state of democracy to the stock of social capital in a society. For example, he attributes the successful functioning of socio-economic life in northern Italy to the high level of social capital in the region and the opposite in the south, and different crime rates in the different states of his own country to the different levels of social capital in those states. In this regard, it would be fair to say that he has paid insufficient attention to the sociological causes of what he saw as the declining stock of social capital, which has been examined by sociologists investigating the determinants of bonding and bridging social capital and concomitants such as trust in capitalist countries like the USA or Britain (e.g., Hall, 1999; Li, Savage, \& Pickles, 2003; Li, 2015; Paxton, 1999).

Sociological critiques of the relationship between social cohesion and social capital offer considerable insights. Cheong et al. (2007), for example, argue that more social capital does not necessarily lead to better social cohesion, as more social capital within groups tends to erode connections with other groups. Thus, for these authors, the 'proposal to (re)create cohesive communities via social capital building may therefore be inter-

\footnotetext{
${ }^{1}$ In the Qatari context, the term "immigrants" is used to refer to guest workers as there is no formal path to citizenship.
} 
preted as a diversion from the fundamental injustices' (Cheong et al., 2007, p. 36). Leonard thinks that even the transition from bonding to bridging social capital will reinforce existing inequalities through the affirmation of their existence and, therefore, 'in order to set in motion the framework for bridging social capital to emerge, the conditions that led to the development of bonding social capital need to be undermined' (2004, p. 927). This view is also echoed by Rajulton, Ravanera and Beaujot (2007), who show that a strong sense of belonging can be associated with low tolerance of diversity. But Rajulton et al. (2007) do not specify what kind of belonging leads to low tolerance. In this paper, we argue and demonstrate that personal belonging among family and kin is different from neighbourhood belonging: the former may be associated with low tolerance whereas the latter may foster tolerance in the Qatari context.

The socio-economic insecurity of individuals and communities has been found in numerous studies to be the main influence behind weak and falling levels of social capital and social cohesion (Fieldhouse \& Johnson, 2008; Letki, 2008; Li et al., 2003). Viewed from this perspective, social cohesion is best achieved by battling poverty and correcting social injustice. A society that acknowledges diversity while ensuring justice and prosperity for all will more likely be a cohesive one. This, of course, does not mean that social connections, social belonging or civic engagement play no role in social cohesion. Beyond economic factors, we may find that bridging social ties and neighbourhood belonging have a positive effect on people's attitudes or behaviour, especially in societies such as Qatar where citizens account for only a small proportion of the population.

Social cohesion is not unidimensional but encompasses different components such as trust and civic participation. Trust between members of society is a precondition for social cohesion. It would be difficult to imagine a well-functioning society composed solely or even predominantly of mutually distrusting and unconnected individuals. Maintaining social cohesion for ethno-culturally diverse societies is even more challenging when waves upon waves of immigrants from various backgrounds, religious traditions, and group identities come to the country. In Qatar, the high level of segregation between Qataris and out-groups offers a good opportunity to study the relationship between social interaction and intergroup cooperation.

A major issue in the conceptualization and measurement of social cohesion concerns individual versus group levels of social interaction (Friedkin, 2004). Individuallevel interaction refers to one's willingness to remain within one's own social group and strengthen ties with it. Group-level cohesion refers to the breadth and depth of ties with out-groups. This is similar to the 'bonding' versus 'bridging' classification made by Putnam, but we can make more refined distinctions. Individual-level cohesion can be further differentiated into personal bonding with family and kin, extended friendship ties with others with similar or dissimilar characteristics, and meso-level acquaintances with neighbours and others in the local community. The effects of these connections on people's attitudes and tolerance may be different: close bonding within family and kin may restrict people's outlook whereas friendship with others, particularly with people of different ethnic backgrounds, may broaden people's horizons, as will a sense of community belonging that bridges to out-groups. Almost all Qataris belong to the same group in terms of racial and religious affiliation; they are Arab Muslims. The traditional and conservative nature of Qatari society and the constant influx of immigrants from non-Arab and non-Muslim backgrounds may lead Qatari nationals to 'hunker down', or become apathetic or even antipathetic towards outsiders, but one might also expect those with bridging ties or a greater sense of neighbourhood belonging to be more openminded. To understand how social cohesion operates in Qatar, we therefore need to understand how social Qataris are and how their identification with in- and outgroups might impact upon attitudes to out-groups.

The discussion of in-group versus out-group relations is related to the differentiation mentioned above between bonding and bridging forms of social capital. In our context, bonding ties can be seen to reflect interaction among Qataris or with the larger Arab groupings. Bridging concerns horizontal ties based on shared interests that go beyond differences of race, religion, and socioeconomic characteristics. In a way, social cohesion can be reached by realising the benefit of cross-community relations: the more the different social groups in a society work together, the higher the likelihood that all groups will benefit. In Qatar, the realisation of nationallevel social cohesion needs more bridging connections across groups, namely, between Qataris and immigrants who are different from them culturally.

Building strong bridging social capital is a way to ensure that the benefits of bonding social capital become society-wide rather than group specific. As Pieterse (2003) says, for bonding social capital to yield positive outcomes, bridging social ties need to be strong. Some authors, such as Leonard (2004) and Rajulton et al. (2007), also point to the potentially negative effects of bonding ties on social cohesion through increased prejudice towards members of out-groups, which is likely to develop when there are strong ties within tightly knit communities (see also Portes \& Landolt, 1996). In Qatari society, there are many commonalities between Qataris, as almost all of them are Muslims and Arabic speaking. Also, most Qataris are tribally affiliated and therefore strong group ties are apparent (Al-Kathim, 1991). Apart from ethno-religious differences, immigrants in Qatar, and especially non-Arabs, are also socially segregated from Qataris through economic status, living conditions, and cultural boundaries. This social setting encourages each group to remain in their own spheres of life, which is not conducive to inter-group interactions. Qataris share strong ties amongst themselves due to tribal affiliations 
and a specific image that includes traditions and religion as the core national identity. Yet, Qataris and immigrants also share workplaces, neighbourhoods and even the education system, making inter-group tensions and associated problems more likely to occur. Therefore, it is of considerable importance, in our context, to understand how the strong intragroup ties among Qataris affect their attitudes to immigrant groups.

One of the key indicators of social cohesion is social trust at the macro (generalized) and meso (situational) levels (Li, Pickles, \& Savage, 2005). Defining trust in the Arab context is no easy task. As the Arabic proverb goes, 'the most complicated of tasks is explaining that which is in no need of explanation'. Trust is a word we frequently use in our parlance and, more importantly, a practice that we even take for granted in much of our social life, a situation which is made possible through repeated social interactions.

Deutsch (1958) suggests that due to the expectation of a positive outcome, the trusting party would be more affected by betrayal of trust than affirmation of it. If you trust someone, you have decided beforehand that the outcome will be positive. If you are in doubt about the positive outcome you don't have trust. Trust is therefore a relationship between two actors, the first extending trust and the second receiving it (Baier, 1986; Hardin, 1993; Luhmann, 1980). This relationship centres on the belief that the second party will react positively to trust by delivering on the subject of trust in a material or sentimental manner.

The concept of trust explains why one would take risks in dealing with others, participate in solving collective problems, or act in ways that seem to be in conflict with the definition of self-interest (Levi \& Stoker, 2000). It has also been argued that it is sometimes in our own interest to trust, as this enables us to gain access to benefits that accrue when we deal with other people, lowers the cost of everyday business, and fosters reciprocation by others (Alesina \& La Ferrara, 2002). Trust is mutually beneficial when it is reciprocal, when the trusting and the trusted parties act according to expectation. In highly diverse settings, the prospect of cross-group cooperation may be hampered by differences and tensions between groups. As earlier noted, the presence of trust presumes a predisposition to cooperation and a relative absence of tensions. For our study, this is the desired outcome, a state of mutual predisposition to cooperate and work together between Qatari citizens and non-citizen residents in Qatar.

It is therefore plausible to suggest that trust is a rational choice whereby both parties can expect to gain from the relationship. It is in the interest of the trusted party to maintain the trustworthy status through delivering on expectation (Guth, Levati, \& Ploner, 2008). When the trust cycle is broken, both parties lose out. This is why social trust is seen by researchers as being sociological rather than psychological or purely economic (Lewis \& Weigert, 1985). It is a result of social actions and repeated inter- actions. In order to get by and get ahead in our personal and social life, we need to work together and trust one another (Arrow, 1972).

However, just as with many other social factors, trust may have a downside. Bad, or so-called 'blind', trust is a situation where the trusting party extends trust without receiving the desired results from the trusted party because of the personal or ideological dispositions of the latter. This bad trust could lead to manipulative political and religious figures advancing their own agendas, which could do much damage to the social fabric. Arguably, voting for someone is partly a manifestation of trust that the candidate will deliver on his or her promises. Many Germans in the 1930s placed their trust in the Nazis and their leader to solve the country's economic, social and political problems, but that trust led to a disaster for the world.

Good trust is the focus of our study. By this, we mean the kind of trust that encourages cooperation between members of different groups in society regardless of race, religion or nationality. Understanding what trust exists between Qataris and migrant workers and what factors affect it is the first step in advancing social cohesion. Good trust reaps the benefits of a cooperative society and avoids the dangers of prejudice and non-cooperation.

Trust as a measure in survey research has taken many forms. With regard to trusted parties, researchers identify three domains: trust in those we know, trust in institutions, and trust in undefined others. The first kind of trust, sometimes called familial, particular or thick trust (Delhey, Newton, \& Welzel, 2011; Field, 2008; Levi \& Stoker, 2000; Li, Heath, \& Devine, 2015), is direct: the trusted party is known and the relationship is easily explained. Repeated co-operation within the inner circle provides an abundance of the information necessary for people to decide whether or not to trust someone (Stolle, Soroka, \& Johnston, 2008). The second kind of trust, referred to as trust in political institutions (legislative, executive, and administrative bodies), is also fairly stable as such institutions have evolved over dozens or hundreds of years. However, trust in the office-holders could vary (Paxton, 1999). The final domain is commonly known as generalised trust, namely, trust in others with whom one has had no prior interaction. This concept is widely used in social science literature. Stole defines it as 'the potential readiness of citizens to cooperate with each other and [the] abstract preparedness to engage in civic endeavours with each other' (Stolle et al., 2008, p. 4).

Whilst some scholars regard generalised trust as inherently good, it is not without its critics. Arneil (2006), for example, argues that while generalised trust might function well in homogeneous societies, it is not as effective in ethnically diverse settings. This may be especially true in Qatar where the population is clearly divided into Qataris, white-collar, and blue-collar migrant workers, with racial and religious divides. Results from the Social Capital survey in Qatar (2011) show that levels 
of generalised trust vary a great deal between the three groups. Qataris exhibited the highest levels of trust while blue-collar workers showed the least. This is intensified by the high levels of in-group trust and the extremely low levels of out-group trust.

The high level of trust shown by Qataris merits closer scrutiny. As Wilson (n.d.) says, a respondent may often be thinking of the intra-group relations when prompted to assess his or her trust in unspecified 'others' and therefore the answer may not accurately reflect the level of inter-group trust in society. This was confirmed by the fact that the level of generalised trust and of Qataris' trust in Qataris was similar but it dropped significantly when discussing out-groups (Al-Emadi, Diop, Le, Al-Ansari, Jardina, Tessler, \& Wittrock, 2011; Diop, Jardina, Tessler, \& Wittrock, 2016).

These considerations on personal trust focus on the radius of trust, whereas the level of trust in the civic sphere relates to the intensity of civic cooperation in a society, which may or may not depend on personal acquaintance between fellow members in civic organisations. By analysing indicators of in-group and out-group trust, Delhey et al. (2011) conclude that it is possible to control for radius of trust. Their results suggest that societies with more familial and tribal ties tend to have a narrow radius of trust while more advanced societies exhibit a wider radius.

As Qatari society is highly familial and tribal, the expectation is that the strong social divide between Qataris and immigrants will yield a narrow radius of generalised trust that focuses on Qataris as a community rather than extending trust to the overall, highly diverse society. Qataris view themselves as 'the' group in society as they are citizens of the country while all others are simply sojourners. Yet, as they live in proximity to these immigrants, their perception of the 'general' public is also hampered by the way society is structured. For Qataris, it is easier to view society in a segmented way: Qataris and highly integrated Arabs; white-collar non-Arabs, who mostly interact with Qataris in the workplace and in educational institutions; and blue-collar workers, who very rarely have personal contact with Qataris (Diop, Le, Johnston, \& Ewers, 2016). Overlaid on this economic divide are cultural differences, with much greater preference shown for Arabs than for Westerners and Asians. Given this, invoking particularised trust by asking Qataris about their trust in specific out-groups, identified by their background, is better suited to our research questions.

Underlying particularised trust is the extent of contact which a member of mainstream society has with members of out-groups, as has been demonstrated by much of the previous research (Forbes, 1997; Putnam, 2007; Schmid, Al Ramiah, \& Hewstone, 2014; Sigelman \& Welch, 1993; Stein, Post, \& Rinden, 2000). In Qatar, contact is of prime importance as different groups have different contact dynamics with Qataris. Arabs are more integrated, as they speak the same language as Qataris and share many social and cultural norms. Asians are usually found in low-skilled jobs which don't give them many opportunities to have contact with Qatari nationals. Westerners, on the other hand, share very little with Qataris as most of them do not speak Arabic, do not live in Qatari neighbourhoods, and their children do not attend public schools. However, they are more likely than Asians to interact with Qatari nationals in the workplace as they are usually engaged in white-collar work. This social setting requires a measurement of contact that acknowledges these different dynamics.

Another factor in the Qatari context is related to religious affiliation. Religiosity and religious practice have been found to have a significant impact on inter-group trust (Alesina \& La Ferrara, 2002; Brambilla, Manzi, Regalia, \& Verkuyten, 2013; Brenneman, 2008; Schmeets \& Te Riele, 2014; Schoenfeld, 1978; Traunmuller, 2011). The religiously conservative nature of Qatari society encourages an exploration of the relationship between religion and trust as immigrant groups include both Muslims and non-Muslims. However, religion is not the only aspect of Qataris' conservatism: social norms are also highly important to Qataris.

Social conservatism and social attitudes in general affect social trust, especially towards immigrants. Low trust in members of other groups has been attributed to strong adherence to group-specific norms (Dawes, Van de Kragt, \& Orbell, 1988; Uslaner \& Conley, 2003). The strong tribal nature of Qatari society elevates the significance of social conservatism as social norms for gaining an understanding of trust between Qataris and immigrants. However, it is also important to note that the increased presence of civic organisations and charities may increase the likelihood of Qataris interacting with immigrants in a new setting where more or less equal status is apparent through volunteering and charitable work.

The ever-changing social (and political) milieu is also important for understanding social trust. Immigration is becoming an increasingly important political issue in many parts of the world but, in the Qatari context, political orientation is difficult to gauge, as no political parties exist in the country. Nevertheless, the Arab Spring and the resulting chaos in the region have had a notable impact on all Arab countries and Qatar is no exception. ProIslamist and anti-Islamist propaganda flooded Arab media and generated high levels of public interest in Qatar. This allows us to test for the effects of Islamism manifested as, for example, a desire for out-groups to adopt Qatari customs.

The above discussions offer various ways in which we could seek to understand social trust and social attitudes in Qatar. Many of the factors are, of course, intertwined in the Qatari context. Understanding how religious, social, and political attitudes impact one another is necessary in order to determine how significant these effects are and which of them holds greater importance in explaining trust in and attitudes to immigrants and social inclusion. 


\section{Hypotheses}

Based on the literature review, we have developed a number of hypotheses in order to explain Qataris' preferences for having Arab and Western expatriate families as next-door neighbours and the impact of religiosity, social capital, and civic engagement on these preferences. For this purpose, we use separate models for each group (Arab and Western families) and estimate a series of logistic regression models. For each subgroup, the base model (Model 1) contains individual, household, and regional characteristics as control variables, including gender, marital status, education, age, employment, household income, region, and year of survey.

Model 2 introduces attitudinal and behavioural dimensions of religiosity. The former is self-reported religiosity. All respondents were asked to describe themselves as very religious, moderately religious, somewhat religious, or not religious at all. This variable is dichotomized with 1 indicating 'very religious' and 0 otherwise. For the behavioural dimension of religiosity, respondents were asked how often they go to a place of worship, with answers ranging from daily, more than once a week, once a week, once a month, more than once a month, a few times a year, to seldom or never. This variable is also dichotomized, with 1 for daily and more than once a week, and 0 for the other responses. Drawing on our discussions above, we can formulate our hypotheses as follows.

Hypothesis 1.1: Religiosity is positively related to preferences for having Arab families as next-door neighbours, with greater religiosity associated with stronger preferences.

Hypothesis 1.2: Religiosity is negatively related to preferences for having Western families as next-door neighbours, with higher religiosity associated with weaker preferences.

The multitude of items discussed above can, following Putnam (2000) and Li (2015), be grouped into what might be termed 'core' and 'derived' domains of social capital. The former includes items such as social ties and relationships constitutive of social networks per se and the latter includes outcomes of being embedded in such networks such as trust, preferences for assimilation and, for our present purposes, preferences for neighbours. Based on the two domains, we present the regression in the sequence which follows. ${ }^{2}$

The third model, Model 3, introduces elements of family and friendship networks into the model. The family network tests whether the family-inward orientation of Qataris has a negative impact on their preferences for next-door neighbours and the friendship network tests whether the diversity of close friends is associated with a positive impact on preferences for having Arab or Western families as next-door neighbours. With regards to familyinward orientation, respondents were asked how often they get together with family members including siblings or extended kin for a social event or family occasion. Responses with 'daily' and 'more than once a week' frequencies are coded as 1 and other responses as 0 . As for friendship networks, the variable is coded as 1 if respondents have mixed friends, including Qataris, Arabs, Westerners or friends living in other countries, and 0 otherwise.

Hypothesis 2.1: Family-inward orientation is associated with weaker preferences for having Arab/ /Western families as next-door neighbours.

Hypothesis 2.2: Diversity of close personal friends is associated with stronger preferences for having Arab/Western families as next-door neighbours.

The fourth model, Model 4, introduces elements of civic engagement and tests whether volunteering for civic organizations or donating to charities has a positive impact on Qataris' preferences for having Arab and Western families as next-door neighbours. Respondents were asked whether they had volunteered to civic organizations and whether they had donated to charities. Both questions used the twelve-month period preceding data collection as a time reference for each wave. The two variables are also dichotomized with 1 indicating positive, and 0 negative, responses.

Hypothesis 3: A high degree of civic engagement is associated with stronger preferences for having Arab/Western families as next-door neighbours.

The fifth model, Model 5, tests whether generalised trust in Arabs/Westerners is associated with Qataris' preferences for having Arab or Western families as next-door neighbours. Trust in Arabs and Westerners was rated on a 0-10-point scale.

Hypothesis 4: Higher levels of trust in Arabs/Westerners are associated with preferences for having Arab/Western families as next-door neighbours, with higher trust associated with stronger preferences.

Model 6 tests whether a desire for out-groups to adopt Qatari customs has a strong impact on Qataris' preferences for having Arab families as neighbours and a weak impact on Qataris' preferences for having Western families as neighbours. All respondents were asked to rate the level of importance of out-groups adopting Qatari customs as part of the requirements for seeking citizenship of Qatar. Responses for this question are coded as 1 for very important and 0 for other responses.

Hypothesis 5.1: The importance Qataris attach to outgroups adopting Qatari customs is associated with

\footnotetext{
${ }^{2}$ We thank the anonymous reviewer who recommended this regression sequence.
} 
stronger preferences for having Arab families as nextdoor neighbours.

Hypothesis 5.2: The importance Qataris attach to outgroups adopting Qatari customs is associated with weaker preferences for having Western families as next-door neighbours.

Model 7 adds the respondents' perception of neighbourhood belonging and Model 8 adds that of neighbourhood cohesion. The belonging question is worded 'I feel accepted as a member of this neighbourhood' on a fourpoint agree/disagree scale. This variable is dichotomized as well, with 1 equalling 'agree' and 0 otherwise. The cohesion question in Model 8 asked respondents whether they agreed or disagreed with the statement: 'People here look out for the welfare of their own families and are not much concerned with neighbourhood welfare.' We recoded the responses so that 1 means cohesive neighbourhood, namely, that people in the neighbourhood show concern for each other's welfare, and 0 otherwise.

Hypothesis 6: A positive sense of neighbourhood belonging is associated with stronger preferences for having Arab/Western families as next-door neighbours.

Hypothesis 7: A positive perception of neighbourhood cohesion is associated with stronger preferences for having Arab/Western families as next-door neighbours.

\section{Data and Results}

Our analysis draws on data from the first two waves of the survey 'From Fareej to Metropolis: A Social Capital Survey of Qatar' conducted by the SESRI at Qatar University in 2011 and 2015 respectively. Both waves were funded by the Qatar Foundation for Education, Science and Community Development. The survey adopted multi-stage stratified probability sampling and collected information on representative samples of the Qatari population focussing on three groups: Qatari citizens, highskilled migrant workers, and low-skilled migrant workers. Overall, 4,821 interviews were completed between the two waves (2,268 in the year 2011 and 2,553 in the year 2015) including a total of 1,631 Qatari nationals, 1,605 high-skilled workers, and 1,585 low-skilled migrant workers. To explore the effects of social capital, religiosity, and civic engagement on Qataris' preferences for having Arab or Western families as next-door neighbours, we restricted our analysis to data on the Qatari citizen sub-samples. The response rates were high $(61 \%$ and $59 \%$ respectively). The data were weighted to account for probability selection and non-response. The analysis used in this paper is based on weighted data using STATA (version 14), which takes into account the survey design effect.
The survey asked a variety of questions on preferences from which we selected two as our outcome variables-preferences for having Arab and Western families as next-door neighbours. More specifically, respondents were asked whether they would have a 'strong preference, slight preference, neither a preference nor an objection, slight objection, or strong objection for having Arab families as their next-door neighbours.' And they were asked the same question about Western families. The two variables are dichotomized-1 for strong preference, and 0 for the other response modes-and are used as our dependent variables in this analysis using logit models (further analysis using ordinal logit models yielded basically the same patterns). Our explanatory variables are summarized in Table 1.

Table 2 presents the descriptive statistics for the variables listed in Table 1. Results from the substantive analyses are presented in Tables 3 and 4 with regard to Qataris' preferences for having Arab and Western families as nextdoor neighbours respectively. Data in the last two tables pertain to average marginal effects (AMEs) derived from the logit models. While substantively the same, the AMEs show the effects in terms of percentage points rather than log odds as in logit models, offering easier exposition. Overall, only one in four Qataris (25\%) wish to have Westerners as next-door neighbours, but over twice as many (55\%) are happy to have Arabs as nextdoor neighbours.

Most empirical studies tend to explain findings in sequence. As our aim in this paper is to explain the sociocultural determinants of Qataris' preferences for having Arab and Western expatriate families as next-door neighbours as a dual dimension, it makes more sense to make an exposition of the effects of our independent variables on the two groups simultaneously. We have also conducted prior analyses on bivariate associations and found that all our independent variables are significantly associated with both kinds of preference (with the sole exception of gender on preferences for Arabs). To save space, we thus move directly to multivariate analyses as shown in Tables 3 and 4 respectively.

With regard to individual and household characteristics in the two tables, we can see that, in terms of net effects, most variables in this domain (marital, employment and financial status, gender, age, education) do not have notable effects: none of the variables are significant with regard to preferences for Arabs in any of the eight models in Table 3 (with the sole exception of richer families unwilling to have Arab neighbours in Model 8); and most of them have non-significant effects with regard to preferences for Westerners (with the exception of older and employed Qataris being less welcoming but richer Qataris more receptive in the first four models). With regard to regional differences, Qataris residing in al Rayyan and other municipalities have stronger preferences for having Arab families as next-door neighbours as compared to those residing in Doha (Table 3). As for Western families, Qataris living in Al Rayyan are little dif- 


\section{COGITATIO}

Table 1. Dimensions and indicators.

\begin{tabular}{ll}
\hline Dimensions & Indicators \\
\hline Demographic & - Individual characteristics \\
& - Household characteristics \\
& - Year of survey \\
& - Municipalities \\
\hline Religiosity & - Self-reported religiosity \\
& - Frequency of going to places of worship \\
\hline Trust & - Trust in Arabs \\
\hline Networks & - Trust in Westerners \\
\hline Q Frequency of getting together with family members & - Diversity of close personal friends \\
\hline Civism & - Preferences of "adopting the customs of Qatar" for somebody seeking citizenship of Qatar \\
\hline Neighbourhood belonging & - Feeling of being accepted as a member of the neighbourhood \\
\hline Neighbourhood cohesion & • People in the neighbourhood only look out for their own welfare and are \\
(reverse-coding) & not concerned with neighbours' welfare \\
\hline
\end{tabular}

Table 2. Descriptive statistics.

\begin{tabular}{|c|c|c|c|c|}
\hline Variables & $\mathbf{N}$ & Percentage & & \\
\hline Male & 1631 & $45 \%$ & & \\
\hline Married & 1631 & $71 \%$ & & \\
\hline Employed & 1630 & $49 \%$ & & \\
\hline Household income $\geq 50,000$ QAR & 1516 & $48 \%$ & & \\
\hline Very religious & 1629 & $18 \%$ & & \\
\hline Daily attendance of place of worship & 1624 & $43 \%$ & & \\
\hline Getting together with family members on a daily basis & 1619 & $74 \%$ & & \\
\hline Diversity of friends (yes) & 1631 & $62 \%$ & & \\
\hline Qatari customs for immigrants (very important) & 1603 & $61 \%$ & & \\
\hline Volunteering (yes) & 1626 & $22 \%$ & & \\
\hline Charitable Donations (yes) & 1601 & $76 \%$ & & \\
\hline Neighbourhood belonging (yes) & 1605 & $81 \%$ & & \\
\hline Neighbourhood cohesion (yes) & 1601 & $36 \%$ & & \\
\hline \multicolumn{5}{|l|}{ Education } \\
\hline Vocational or less & 461 & $30 \%$ & & \\
\hline Secondary \& post-secondary & 598 & $36 \%$ & & \\
\hline University degree, Masters, \& Ph.D. & 571 & $34 \%$ & & \\
\hline \multicolumn{5}{|l|}{ Age } \\
\hline 30 years or younger & 452 & $28 \%$ & & \\
\hline $31-44$ years & 548 & $31 \%$ & & \\
\hline 45 years or older & 585 & $41 \%$ & & \\
\hline \multicolumn{5}{|l|}{ Municipality } \\
\hline Doha & 540 & $34 \%$ & & \\
\hline Al Rayyan & 708 & $42 \%$ & & \\
\hline \multirow[t]{2}{*}{ Other municipalities } & 383 & $24 \%$ & & \\
\hline & $\mathrm{N}$ & Min & Max & Mean \\
\hline Trust in Arabs & 1597 & 0 & 10 & 6.448 \\
\hline Trust in Westerners & 1470 & 0 & 10 & 4.132 \\
\hline
\end{tabular}


Table 3. Average marginal effects (AME) of Qataris' preferences for having Arab families as next-door neighbours.

\begin{tabular}{|c|c|c|c|c|c|c|c|c|}
\hline Variables & Model1 & Model2 & Model3 & Model4 & Model5 & Model6 & Model7 & Model8 \\
\hline Male & 0.5 & 3.2 & 2.5 & 2.8 & 2.7 & 1.6 & 2.1 & 1.1 \\
\hline Married & -4.7 & -4.5 & -4.3 & -5.0 & -4.0 & -4.3 & -3.0 & -3.3 \\
\hline Secondary & 1.0 & 0.8 & 0.4 & -0.2 & -1.6 & -1.2 & -2.5 & -2.1 \\
\hline Tertiary & 3.1 & 3.4 & 2.6 & 2.1 & -0.2 & 0.1 & -0.2 & 0.6 \\
\hline Aged 31-44 & 1.2 & 0.8 & 0.9 & 0.4 & -0.5 & -0.2 & -1.0 & -1.0 \\
\hline Aged 45+ & 0.8 & 1.5 & 1.2 & 0.9 & 0.1 & -0.4 & -1.3 & -0.1 \\
\hline Employed & 2.0 & 2.2 & 2.1 & 1.9 & 2.0 & 2.2 & 2.1 & 2.1 \\
\hline Household income $\geq 50,000 Q A R$ & -3.8 & -3.9 & -3.4 & -3.9 & -3 & -3.2 & -4.3 & $-5.4^{b}$ \\
\hline Living in Al Rayyan & $6.6^{c}$ & $7.5^{b}$ & $7.5^{b}$ & $7.2^{b}$ & $7.1^{b}$ & $7.6^{b}$ & $7.0^{\mathrm{b}}$ & $7.6^{b}$ \\
\hline Living in other areas & $7.1^{c}$ & $8.1^{b}$ & $7.3^{c}$ & $7.0^{c}$ & $7.5^{c}$ & $7.2^{\mathrm{c}}$ & $7.0^{\mathrm{c}}$ & 6.0 \\
\hline Year of survey (2015) & $10.3^{a}$ & $9.6^{a}$ & $9.3^{a}$ & $8.8^{a}$ & $7.3^{b}$ & $8.4^{a}$ & $8.9^{a}$ & $8.9^{a}$ \\
\hline Religiosity & & $-7.1^{c}$ & $-6.9^{c}$ & $-6.8^{c}$ & $-6.9^{c}$ & $-7.4^{c}$ & $-8.4^{b}$ & $-8.7^{b}$ \\
\hline Religious attendance & & -3.3 & -3.7 & -4.0 & -4.0 & -2.6 & -3.9 & -3.0 \\
\hline Getting together with family and kin & & & -2.5 & -2.4 & -2.8 & -3.2 & -4.6 & -5.0 \\
\hline Diversity of friends & & & 4.7 & 4.8 & $5.4^{c}$ & $5.4^{c}$ & 4.5 & 4.0 \\
\hline Volunteering & & & & 4.6 & 4.3 & 4.5 & 4.1 & 4.4 \\
\hline Donations & & & & 5.3 & 4.4 & 3.9 & 3.1 & 3.8 \\
\hline Trust in Arabs & & & & & $3.1^{a}$ & $2.9^{a}$ & $2.8^{a}$ & $2.8^{a}$ \\
\hline Qatari customs for immigrants & & & & & & $8.3^{a}$ & $7.7^{b}$ & $7.6^{b}$ \\
\hline Neighbourhood belonging & & & & & & & $10.8^{a}$ & $11.2^{\mathrm{a}}$ \\
\hline Neighbourhood cohesion & & & & & & & & 4.7 \\
\hline Wald $\chi^{2}$ & 23.35 & 28.57 & 30.15 & 35.38 & 58.78 & 69.38 & 75.09 & 82.44 \\
\hline McFadden's Adj R ${ }^{2}$ & 0.014 & 0.017 & 0.018 & 0.021 & 0.038 & 0.043 & 0.049 & 0.054 \\
\hline $\mathrm{N}$ & 1479 & 1471 & 1462 & 1441 & 1420 & 1402 & 1382 & 1367 \\
\hline
\end{tabular}

Notes: ${ }^{a} \mathrm{p}<.01,{ }^{b} \mathrm{p}<.05,{ }^{\mathrm{c}} \mathrm{p}<.10$; Reference categories are female, non-married, with primary education, age under 30 , non-employed, household income $\leq 50,000$ QAR, living in Doha, survey year 2011, less religious, with less bonding and bridging ties, less desirous of foreigners adopting Qatari customs, less volunteering and donating, and less attached to the neighbourhood; 1 QAR = 0.27 US Dollar.

ferent from those living in Doha and only those living in other municipalities show positive preferences for having Westerners as next-door neighbours (Table 4). These results suggest that Qataris residing in Doha are less keen to have them as next-door neighbours.

With reference to the waves, the results show a positive and significant (at 0.1 level) effect for the year (2015) variable in all models, indicating improved Qatari attitudes towards Arab and Western families between 2011 and 2015. This pattern is in line with two major changes that occurred during that period, namely, the awarding of the FIFA 2022 World Cup and a 60 percent salary increase for Qatari nationals. Though the announcement of Qatar hosting the 2022 FIFA World Cup was made in December 2010, it was around 2015 that outside scrutiny and criticism of Qatar's policies with respect to the treatment and welfare of its guest workers reached a critical point and required a response. This in turn increased awareness of migrant workers' issues among Qatari nationals. In addition, in 2011 the government increased the salary of Qatari nationals by 60 per cent. Taken together, these two events may have contributed to the change in nationals' attitudes towards both Arab and Western expatriate families. The national mood was happier and more welcoming of guest workers.

Turning to religiosity and religious attendance, we find a weak and negative association with preferences for having Arab or Western expatriate families as neighbours, with religiosity effects barely significant (at 0.1 level) for Arabs, indicating that Qatari nationals who consider themselves very religious are less likely to want Arab families living next-door. This is an unexpected result as Qataris and most Arabs share the same language and religion.

Family and friendship networks seem to play an important role. Family-inward orientation has no significant (albeit weakly negative) bearing on the Arab models but, as might be expected, a strong and significantly negative impact on Western expatriate families, indicating that strong bonds amongst family members tend to make Qatari nationals more disinclined to accept Western expatriate families as next-door neighbours. By contrast, we find in both tables that bridging social capital, as indicated by a diversity of friendship networks, tends to make Qataris more open and more willing to accept both groups as next-door neighbours, and indeed, more so for Westerners than for Arabs: around 10 percentage points for Westerners and 5 percentage points for Arabs. Whereas the impact is significant in early models (5 and 6) for Arabs, the effect becomes non-significant with models 7 and 8 . On the other hand, the effect is fully significant for all models 4-8 with regard to Western families. Further analysis shows that the net effects of friendship diversity are significantly stronger for West- 
Table 4. Average marginal effects (AME) of Qataris' preferences for having Western families as next-door neighbours.

\begin{tabular}{|c|c|c|c|c|c|c|c|c|}
\hline Variables & Model1 & Model2 & Model3 & Model4 & Model5 & Model6 & Model7 & Model8 \\
\hline Male & -0.4 & -0.4 & -0.5 & -0.3 & 0.4 & 0.5 & 1.1 & -0.6 \\
\hline Married & 0.5 & 0.5 & 0.8 & 1.0 & 0.5 & 0.3 & 1.2 & 0.9 \\
\hline Secondary & 4.1 & 4.1 & 3.4 & 2.7 & 1.4 & 2.6 & 1.7 & 2.0 \\
\hline Tertiary & 4.0 & 4.0 & 2.5 & 2.1 & 0.2 & 1.5 & 1.2 & 1.2 \\
\hline Aged 31-44 & -2.5 & -2.5 & -3.8 & -3.6 & -3.6 & -3.5 & -4.3 & -3.3 \\
\hline Aged 45+ & $-6.5^{c}$ & -6.2 & $-7.4^{c}$ & $-7.2^{c}$ & $-8.0^{b}$ & $-8.3^{b}$ & $-8.6^{b}$ & $-7.6^{c}$ \\
\hline Employed & -3.5 & -3.5 & -4.1 & -3.9 & $-5.2^{b}$ & -4.9 & -4.4 & -5.0 \\
\hline Household income $\geq 50,000 Q A R$ & $4.8^{c}$ & $5 \mathrm{c}$ & $5.7^{b}$ & $5.8^{b}$ & 4.1 & 3.9 & 3.7 & 3.0 \\
\hline Living in Al Rayyan & 1.7 & 2.0 & 3.0 & 3.0 & 3.6 & 3.7 & 3.4 & 4.8 \\
\hline Living in other areas & $11.5^{a}$ & $11.9^{a}$ & $10.5^{a}$ & $10.0^{a}$ & $11.7^{a}$ & $11.4^{\mathrm{a}}$ & $11.6^{\mathrm{a}}$ & $10.1^{a}$ \\
\hline Year of survey (2015) & $11.4^{\mathrm{a}}$ & $11.1^{\mathrm{a}}$ & $10.8^{a}$ & $10.6^{a}$ & $8.8^{a}$ & $9.9^{a}$ & $10.1^{a}$ & $9.6^{a}$ \\
\hline Religiosity & & -3.0 & -2.3 & -2.7 & -2.1 & -2.2 & -2.3 & -2.1 \\
\hline Religious attendance & & 0.3 & -0.7 & -1.4 & -1.6 & -1.7 & -3.5 & -1.8 \\
\hline Getting together with family and kin & & & $-8.5^{a}$ & $-8.4^{a}$ & $-8.4^{a}$ & $-8.2^{a}$ & $-9.1^{a}$ & $-9.2^{a}$ \\
\hline Diversity of friends & & & $10.5^{\mathrm{a}}$ & $11.1^{\mathrm{a}}$ & $9.5^{\mathrm{a}}$ & $10.0^{a}$ & $9.1^{a}$ & $8.9^{a}$ \\
\hline Volunteering & & & & 2.4 & 1.7 & 2.0 & 1.3 & 1.6 \\
\hline Donations & & & & 1.9 & 1.8 & 1.5 & 0.7 & 1.5 \\
\hline Trust in Westerners & & & & & $2.9^{a}$ & $2.8^{a}$ & $2.8^{a}$ & $2.8^{a}$ \\
\hline Qatari customs for immigrants & & & & & & 4.0 & 3.1 & 3.0 \\
\hline Neighbourhood belonging & & & & & & & $10.1^{a}$ & $10.3^{a}$ \\
\hline Neighbourhood cohesion & & & & & & & & $10.9^{a}$ \\
\hline Wald $\chi^{2}$ & 37.92 & 38.02 & 59.72 & 62.02 & 93.49 & 95.56 & 101.76 & 112.58 \\
\hline McFadden's Adj $R^{2}$ & 0.031 & 0.032 & 0.050 & 0.051 & 0.087 & 0.091 & 0.097 & 0.110 \\
\hline $\mathrm{N}$ & 1479 & 1471 & 1462 & 1441 & 1310 & 1295 & 1279 & 1267 \\
\hline
\end{tabular}

Notes: ${ }^{a} \mathrm{pv}<.01,{ }^{b} \mathrm{p}<.05,{ }^{\mathrm{c}} \mathrm{p}<.10$; Reference categories are female, non-married, with primary education, age under 30 , nonemployed, household income $\leq 50,000$ QAR, living in Doha, survey year 2011, less religious, with less bonding and bridging ties, less desirous of foreigners adopting Qatari customs, less volunteering and donating, and less attached to the neighbourhood; 1 QAR = 0.27 US Dollar.

erners than for Arabs across all models 3-8 (all significant at 0.1 level), which demonstrates the powerful effects of bridging social capital amongst Qatari nationals on acceptance of Western expatriates.

Existing studies of social capital highlight the role of a strong civil society through which individuals who actively participate in political and social life learn how to work with others to solve collective problems and, in the process, become more open-minded, tolerant, trusting and trustworthy, and more welcoming to fellow citizens and people from other countries (Diop, Jardina, et al., 2016; Jamal, 2006; Li \& Marsh, 2008; Li, Savage, \& Warde, 2008; Putnam, 2000). Given this, we might expect Qataris who volunteer and/or donate to charity and other organizations to exhibit stronger preferences for having Arab and Western families as next-door neighbours. However, as can be seen from the results (Model 4), volunteering and donations to charity play no significant role in this regard. This, of course, does not in itself constitute a simple rejection of the role of civic engagement in Qatari society. Our sample size is fairly small and we have included many variables, making it difficult for weak impacts to reach conventional levels of significance. There are signs of positive effects in both tables in this regard and further analysis shows, as noted above, that charitable giving does enhance the Qatari accep- tance of Arabs (57\% of givers compared to $50 \%$ of nongivers being happy to see Arabs as neighbours, p. 0.026).

As discussed above, trust is viewed in much of the social capital scholarship as a vital ingredient of social interaction that generates mutual benefits (Coleman, 1988; Field, 2008; Fukuyama, 1995; Putnam, 1993; Woolcock, 1998). With regards to attitudes towards immigrants, previous studies have shown that nationals with higher levels of trust-variously defined as generalized trust, social trust, or personal trust-tend to hold positive attitudes towards immigrants. These findings are supported by our results with both Arab and Western expatriate families. Trust in both groups has a strong predictive power. Overall, Qataris exhibit different levels of trust towards the different subgroups that comprise the expatriate population in Qatar. Though this level of trust has increased significantly between the two waves, it is much higher for Arabs than for Westerners although the rate of increase is higher for the latter. On the 0 to 10-point scale, Qataris' trust of Arabs increased from 6.18 in 2011 to 6.66 in 2015 while trust of Westerners increased from 3.57 in 2011 to 4.63 in 2015.

Regarding the importance Qataris attach to outgroups adopting Qatari customs as a requirement for obtaining citizenship, Qatari nationals seem to be more flexible with Western families. The variable is significant 
only for Arab families. Qataris who have a strong desire for people seeking citizenship of Qatar to adopt Qatari customs are here shown to favour Arab families as next-door neighbours but are rather neutral with regard to Westerners.

Neighbourhood belonging, as an indicator of local embeddedness or meso-level/situational social capital (Li et al., 2005) is also believed to foster feelings of tolerance and acceptance. Those who perceive their neighbourhoods as cohesive ones where people trust and help one another are also seen as being more open to Westerners. In our data, those with a strong sense of neighbourhood belonging show a strong preference for having Arabs and Westerners as next-door neighbours: around 10 percentage points more in both cases. In addition, those residing in cohesive neighbourhoods are, other things being equal, more willing by 11 percentage points to have Westerners as next-door neighbours.

\section{Conclusion}

While numerous studies have been conducted on the impacts of immigration upon local communities and social cohesion in receiving countries in western developed countries such as the USA and Europe, little research is available on the preferences of nationals in countries where immigrants outnumber the mainstream population. In this paper, we have carried out what we believe is the first systematic study on Qatari nationals' preferences for accepting Arab and Western expatriate families as their next-door neighbours. We use preferences for next-door neighbours as an indicator of tolerance and openness in a highly religious, conservative social context. Drawing on data from nationally representative samples and using a whole range of sociodemographic and cultural variables-including civic engagement, bridging and bonding social ties, as well as social trust-as explanatory variables, we have obtained some important findings. Our main results can be summarized as follows:

- Whilst at the bivariate level most socio-demographic attributes are significantly associated with Qataris' preferences for accepting Arabs and Westerners as next-door neighbours, net effects show that demographic-economic and educational differences do not have salient effects.

- Despite the fact that Qataris are predominantly Muslims, religiosity or practice per se do not have marked effects on Westerner acceptance, though it is weakly significant for accepting Arabs; rather, it is social trust that plays a significant role.

- Bonding social ties tend to be negative, but bridging social ties, in terms of diversity of friends, neighbourhood belonging, and perceived neighbourhood cohesion, are shown to engender greater tolerance and willingness to welcome out-groups.
Overall, while not negating the importance of socioeconomic factors, we find that trust and socially engagement-in terms of diversity of friendship networks and active participation in neighbourhood affairs, which tend to result in a higher sense of belonging and cohesion-are seeds for tolerance, acceptance, and accommodation.

The implications of our research are manifold and we list three here. Firstly, as readers will know, social capital research reached its heights in the early 2000s, after Putnam's (2000) book on Bowling Alone (see Field, 2008, p. 3; Halpern, 2005, p. 9). Academic enthusiasm in this respect seems to have substantially waned in recent years. Scholars' interest may ebb and flow but the underlying social problems persist, as social capital in the form of trust and bridging ties show significant net effects even in a society where nationals comprise a relatively small proportion of the population such as Qatar. Seen from this perspective, we believe that our analysis has rendered a positive service, if not in reinstating the importance of social capital research, but at least in demonstrating the continued relevance of the concept of social capital in social life.

Secondly, as noted in earlier discussions, political scientists and sociologists seem to have travelled on separate tracks, with the former being more interested in documenting the rise and fall of the national stock of social capital and the relationship with democratic governance, and the latter keener to interrogate the socio-economic determinants of the differential possession of social capital. In the present study, we have managed to link both traditions in a simultaneous way in our comprehensive analysis of the socio-economic-cultural determinants of preferences for accepting out-groups in a fairly intimate way, as next-door neighbours. We have also conducted our analysis at both individual and meso-levels.

Thirdly, in terms of policy implications, we believe that our results on the positive effects of neighbourhood belonging and cohesion on Qatari nationals' acceptance of out-groups could be useful for authorities interested in making the country more welcoming and more inclusive. While it would be difficult to increase people's level of trust (Li et al., 2005; Uslaner, 2008), it might be more feasible to enhance community cohesion at the neighbourhood level.

Overall, while we have shown that social capital does have a significant role to play in enhancing social inclusion in a multi-ethnic and multi-cultural context, we wish to point out that there are many other aspects on which, due to limited space, we have not been able to report. These include findings related to policies on immigrants and their subsequent impact, such as immigrants' sojourner mentality and an associated (un)willingness to interact with nationals. These and other factors could impact on one another, making it more challenging for researchers and for policy-makers alike. We hope to report more findings in due course. 


\section{Acknowledgments}

The authors wish to thank the Qatar National Research Fund (QNRF) for supporting the project titled From Fareej to Metropolis: A Social Capital Survey of Qatar (II) (NPRP7-186-5-021). This publication is one of the outputs from the project. The statements made herein are solely the responsibility of the authors. Any opinions, findings and conclusions or recommendations expressed in this paper are those of the authors and do not necessarily reflect the views of the QNRF.

\section{Conflict of Interests}

The authors declare no conflict of interests.

\section{References}

Alesina, A., \& La Ferrara, E. (2002). Who trusts others? Journal of Public Economics, 85, 207-234.

Al-Emadi, D., Diop, A., Le, K., Al-Ansari, M., Jardina, A., Tessler, M., \& Wittrock, J. (2011). From Fareej to metropolis: A social capital survey of Qatar executive summary report. Doha, Qatar: Social \& Economic Survey Research Institute (SESRI), Qatar University.

Al-Kathim, A. (1991). Residents and immigrant workforce in Qatari society, interaction patterns and perceptions. Cairo, Egypt: Hajar Publishing.

Arneil, B. (2006). Diverse communities: The problem with social capital. Cambridge, UK: Cambridge University Press.

Arrow, K. (1972). Gifts and exchanges. Philosophy \& Public Affairs, 1, 343-362.

Baier, A. (1986). Trust and antitrust. Ethics, 96(2), 231-260.

Bourdieu, P. (1986). The forms of capital. In H. Lauder, P. Brown, J. Dillabough, \& A. H. Halsey (Eds.), Education, globalization and social change (pp. 105-108). Oxford, UK: OUP.

Brambilla, M., Manzi, C., Regalia, C., \& Verkuyten, M. (2013). Religiosity and prejudice: Different patterns for two types of religious internalization. The Journal of Social Psychology, 153(4), 486-498.

Brenneman, R. (2008). Faith and the foreigner: Exploring the impact of religion on immigration attitudes. Saarland: VDM Verlag Dr. Muller.

Cheong, P., Edwards, R., Goulbourne, H., \& Solomos, J. (2007). Immigration, social cohesion and social capital: A critical review. Critical Social Policy, 27(1), 24-49.

Coleman, J. (1988). Social capital in the creation of human capital. American Journal of Sociology, 94, S95-S120.

Dawes, R., Van de Kragt, A., \& Orbell, J. (1988). Not me or thee but we. The importance of group identity in eliciting cooperation in dilemma situations: Experimental manipulations. Acta Pyschologica, 68, 83-97.

Delhey, J., Newton, K., \& Welzel, C. (2011). How gen- eral is trust in "most people"? Solving the radius of trust problem. American Sociological Review, 76(5), 786-807.

Deutsch, M. (1958). Trust and suspicion. Journal of Conflict Resolution, 2(4), 265-279.

Diop, A., Jardina, A., Tessler, M., \& Wittrock, J. (2016). Antecedents of trust among citizens and non-citizens. Journal of International Migration and Integration. doi:10.1007/s12134-016-0474-0

Diop, A., Le, K., Johnston, T., \& Ewers, M. (2016). Citizens' attitudes towards migrant workers in Qatar. Migration and Development, 6(1), 144-160.

Field, J. (2008) Social capital (2nd ed.). Abingdon, UK: Routledge.

Fieldhouse, E., \& Johnson, N. (2008). Social capital and ethnic diversity. In N. Johnson (Ed.), Citizenship, cohesion \& solidarity (pp. 22-33). London, UK: Smith Institute.

Forbes, H. (1997). Ethnic conflict: Commerce, culture, and the contact hypothesis. New Haven, USA: Yale UP.

Friedkin, N. (2004). Social cohesion. Annual Review of Sociology, 30(1), 409-425.

Fukuyama, F. (1995). Trust: Social virtues and the creation of prosperity. New York, USA: Free Press.

Guth, W., Levati, M., \& Ploner, M. (2008). Social identity and trust: An experimental investigation. The Journal of Socio-Economics, 37(4), 1293-1308.

Hall, P. (1999). Social capital in Britain. British Journal of Political Science, 29, 417-461.

Halpern, D. (2005). Social capital. Cambridge, UK: Polity.

Hardin, R. (1993). The street-level epistemology of trust. Politics \& Society, 21(4), 505-529.

Jamal, A. (2006). Reassessing support for Islam and democracy in the Arab world? Evidence from Egypt and Jordan. World Affairs, 169(2), 51-63.

Leonard, M. (2004). Bonding and bridging social capital: Reflections from Belfast. Sociology, 38(5), 927-944.

Letki, N. (2008). Does diversity erode social cohesion? Social capital and race in British neighbourhoods. Political Studies, 56(1), 99-126.

Levi, M., \& Stoker, L. (2000). Political trust and trustworthiness. Annual Review of Political Science, 30, 475-508.

Lewis, D., \& Weigert, A. (1985). Trust as a social reality. Social Forces, 63(4), 967-985.

Li, Y. (2015). Social capital in sociological research: Conceptual rigour and empirical application. In Y. Li (Ed.), The handbook of research methods and applications on social capital (pp. 1-20). Cheltenham, UK: Edward Elgar Publishing.

Li, Y., Heath, A., \& Devine, F. (2015). Formal \& informal social connections in the UK. In Y. Li (Ed.), The handbook of research methods and applications on social capital (pp. 187-203). Cheltenham: Edward Elgar Publishing.

Li, Y., \& Marsh, D. (2008). New forms of political participation: Searching for expert citizens and every- 
day makers. British Journal of Political Sciences, 38(2), 247-272.

Li, Y., Pickles, A., \& Savage, M. (2005). Social capital and social trust in Britain. European Sociological Review, 21(2), 109-123.

Li, Y., Savage, M., \& Pickles, A. (2003). Social capital and social exclusion in England and Wales (1972-1999). British Journal of Sociology, 54(4), 497-526.

Li, Y., Savage, M., \& Warde, A. (2008). Social mobility and social capital in contemporary Britain. British Journal of Sociology, 59(3), 391-411.

Lin, N. (2001). Social capital. Cambridge, UK: Cambridge University Press.

Luhmann, N. (1980). Trust and power. New York: Wiley.

Ministry of Developmental Planning and Statistics. (2016). Qatar monthly statistics report. Doha, Qatar: Ministry of Developmental Planning and Statistics (MDPS).

Paxton, P. (1999). Is social capital declining in the United States? A multiple indicator assessment. American Journal of Sociology, 105, 88-127.

Pieterse, J. (2003). Social capital and migration: Beyond ethnic economies. Ethnicities, 3(1), 29-58.

Portes, A., \& Landolt, P. (1996). The downside of social capital. The American Prospect, 26, 18-21.

Putnam, R. (1993). Making democracy work: Civic tradition in modern Italy. Princeton: Princeton University Press.

Putnam, R. (2000). Bowling alone: The collapse and revival of American community. New York: Simon \& Schuster.

Putnam, R. (2007). E pluribus Unum: Diversity and community in the twenty-first century, the 2006 Johan Skytte Prize Lecture. Scandinavian Political Studies, 30(2), 137-174.

Rajulton, F., Ravanera, Z., \& Beaujot, R. (2007). Measuring social cohesion: An experiment using the Canadian national survey of giving, volunteering, and participating. Social Indicators Research, 80(3), 461-492.

\section{About the Authors}

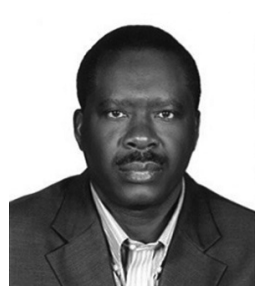

Abdoulaye Diop (PhD) is Research Associate Professor and Head of the Research Department at the Qatar University Social and Economic Survey Research Institute (SESRI). His specific areas of interest include survey research methods, social capital, labor markets and migration and has authored and co-authored a number of publications in these areas. Prior to joining SESRI, Dr. Diop worked at the University of Virginia, the University of Connecticut, and the Advanced School of Applied Economics in Dakar, Senegal.

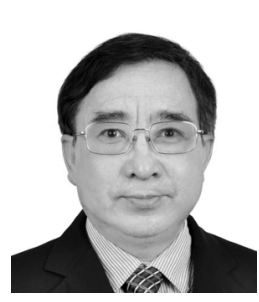

Yaojun Li is Professor of Sociology at the Department of Sociology and the Cathie Marsh Institute for Social Research, Manchester University, UK. His research interests are in social mobility and social stratification, social capital, and the socio-economic integration of ethnic minority groups. He has published widely in these areas, including papers in top sociology journals in Europe and the USA. He has also conducted numerous research projects funded by academic and government agencies in Britain, China, USA, Australia and Qatar. 


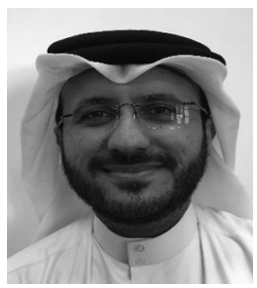

Majed Al-Ansari is a senior researcher with the Social and Economic Research Institute (SESRI) at Qatar University. He received his Doctorate from the University of Manchester in 2017 where his thesis was titled "A Minority of Citizens: The effect of religious, social and political attitudes on trust in immigrants in Qatar". He also received his Master's degree in Social change from Manchester in 2010. Mr. AlAnsari's research interests include Social capital, charitable donations, civil society and social change.

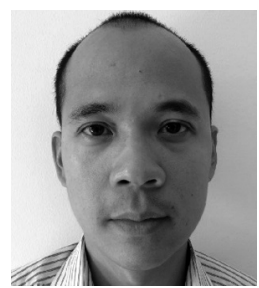

Kien Trung Le earned his PhD in Economics from the University of Virginia in 2008. His research areas are Survey Methodology and Applied Economics. He has publications in both economics and survey methodology journals. Before joining SESRI, Dr. Kien was a researcher at the Weldon Cooper Center for Public Service in the University of Virginia. 